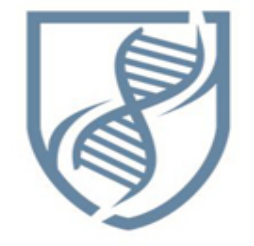

Journal of Bioscience and Applied Research
JBAAR

WWW.JBAAR.ORG

\title{
Age-Related Changes in the Histological Structure of Rabbit Testes and the Prophylactic Role of Vitamin E
}

\author{
${ }^{1}$ Nabila I. El-Desouki, ${ }^{2}$ Amal I. El-Refaiy, ${ }^{1}$ Dalia F. Afifi and ${ }^{1}$ Hanan Talaat \\ ${ }^{1}$ Department of Zoology, Faculty of Science, Tanta University,Tanta, Egypt. \\ ${ }^{2}$ Department of Biological and Environmental Science, Faculty of Home Economic Al-Azhar University, Egypt \\ (Corresponding author. E-mail: nabiladesoky@yahoo.com)
}

\begin{abstract}
The present investigation is planned to compare between the histological structure of rabbit testes of different ages and the prophylactic role of vitamin $\mathrm{E}$ on senescent animals. Male NewZeland rabbits were divided into four groups according to age. Group I: represented the young rabbits (one month age, weighing $1 \pm 0.4 \mathrm{~kg}$ ), group II: adult rabbits ( 6 months age, weighing $4 \pm 0.5 \mathrm{~kg}$ ), group III: aged animals (24 month age, weighing $7.5 \pm 0.5 \mathrm{~kg}$ and group (IV) aged rabbits treated daily with the therapeutic dose of vitamin E orally at a dose of $10 \mathrm{mg} / \mathrm{kg} \mathrm{b.w} \mathrm{/} \mathrm{day} \mathrm{for}$ 60 days. The testes of young rabbits revealed a small form of seminiferous tubules with regular outline with spermatogonia and Sertoli cells, and the lumen appeared empty from spermatozoa. The interstitium is made up of loose connective tissue with large polyhedral interstitial Leydig cells. In adult studied animals, testes demonstrated with all spermatogenic cells and the lumen filled with spermatozoa. In aged rabbits, the histological studies of testis demonstrated atrophied irregular tubules, disarrangement of vacuolated spermatogenic cells, and sloughing of germ cells into the tubular lumen with reduction and degeneration of spermatozoa. The interstitium between the tubules was widen and filled with degenerated and reduced Leydig cells. Administration of vitamin $\mathrm{E}$ to aged animals group revealed an obvious improvement of spermatogenic cells, and the spermatozoa appeared in the lumen of many seminiferous tubules.
\end{abstract}

Keywords: Age, Testis, Histology, Mammals, Vitamin E

\section{Introduction}

The adult mammalian testis performs two important functions, spermatogenesis and male sex hormone production. It is an organ structurally designed to produce the haploid male gametes from diploid postnatal germ-line stem cells, spermatogonia. The process of morphological and functional differentiation of spermatogonia into the haploid spermatozoon, is termed (spermatogenesis). In addition, the testis elaborates a steroid hormone, testosterone that is responsible for maintaining the spermatogenic process. Furthermore, testosterone is important for several different functions in various organ systems including the maintainance of muscle mass and bone density (Ravindranath et al., 2003).

Halawa (2010) stated the histological structure of the testis of adult albino rat and revealed multiple rounded seminiferous tubules with regular outline. They lined by 46 layers of germinal epithelia at different stages of spermatogensis. The flagellae of mature sperms were seen filling the lumens of the seminiferous tubules. The lining epithelium consisted of Sertoli cells, and it appeared pyramidal in shape. Sertoli cells secrete fluids that create a hosbitable environment for spermatozoa which produced continuosly within the seminiferons tubules of the testes. Sertoli cells provide mechanical and nutritive support for the spermatogenic cells (Shokri et al., 2012).

The interstitial spaces in between the tubules contained Leydig cells, fibroblasts and collagenous fibers, macrophages, lymphocytes, mast cells \& blood capillaries (Arking, 2006). Leydig cells secrete male hormone testosterone which responsible for the development of secondary male sex characteristics. Testosterone is synthesized by the enzymes presents in the mitochondria and smooth endoplasmic reticulum (Rolf et al., 2010).

In elderly men, the tubules with hypospermatogonesis (reduced number of elongated spermatids) showed numerous morphological anomalies in the germ cells including multinucleated cells, abnormal germ cells degeneration and Steroli cell vacuolation. These vacuoles correspond to dilations of the extracellular spaces resulting from the premature exfoliation of germ cells (Paniagua et al., 1987; Mahmood, 2008). The number of Leydig cells 
was also decreased in elderly men (Regadera et al., 1993). Moreover, by advancing age, a thickening of the basal membrane, arrested spermatogenesis, the number of germinal and Sertoli cells were decreased as age increased (Dakouane et al., 2005; Talaat, 2016).

It has been hypothesized that aging is associated with mitochondrial enlargement and elongation. These changes may be enhanced by deficiencies in antioxidants, vitaming $\mathrm{E}$ and selenium. Vitamin E supplementation minimizes the age-related mitochondrial changes in the mouse liver (Agostinucci et al., 2002). The effect of antioxidant supplementation in drinking water was studied on sperm quality, lipid peroxidation and testosterone levels of male rats (Sönmez et al., 2005). They recorded the improvement of reproductive traits of male rats that are associated with high fertility. The level of lipid peroxidation is significantly decreased in the testis. Epididymal sperm concentration and plasma testosterone levels are significantly increased in the ascorbic acid treated animals when compared to the control animals.

Vitamin E treatment to aging mice on CatSper genes expression and couhd improve sperm quality and mobility in the testis (Mohammadi et al., 2013). Thus, the present study aimed to compare between the histological structure of rabbit testes of different ages and the prophylactic role of vitamin $\mathrm{E}$ on aged animals.

\section{Materials and Methods \\ Animals:}

Twenty eight different ages of male New Zeland rabbits from one to 24 months weighing from one $\mathrm{kg}$ to 8 $\mathrm{kg}$ were collected during autumn and housed in environmentally controlled optimal conditions for one week. Diet and water were allowed ad-libitium. All care and procedures adopted for the present investigation were in accordance with the approval of the Institutional Animal Ethics Committee of National Research Center and in accordance with recommendation of the proper care and use of laboratory animals.

\section{Experimental design:}

The animals were divided into four groups according to age.

Group I: young rabbits (one month age, weighing $1 \pm 0.4$ $\mathrm{kg).}$

Group II: adult rabbits (6 months age, weighing $4 \pm 0.5$

$\mathrm{kg})$.

Group III: senescent animals (24 month age, weighing 7.5 $\pm 0.5 \mathrm{~kg})$.

Group IV: aged rabbits administered daily with the therapeutic dose of vitamin E orally (E Viton, Kahra Pharm\&Chem.Ind.Co) at a dose of $10 \mathrm{mg} / \mathrm{kg}$ b.w/day for 60 days. Vitamin E (Alpha tocopheryl acetate) dosage was estimated according to Baydas et al. (2002).

The animal groups: I, II \& III were sacrificed after one week, while the animals group (IV) that given with vitamin $\mathrm{E}$ was sacrificed after 60 days. The testes were removed carefully from all groups and cut into small pieces, then fixed in 10\% neutral buffered formalin for 24 hrs for histological studies. Then the fixed specimens were washed and transferred to $70 \%$ ethanol, dehydrated in ascending ethanol,cleared in xylene, embedded in paraffin wax and sectiond at $5 \mu$ thickness. Paraffin sections were used for the histological staining methods by using haematoxylin \& eosin (H\&E) according to Bancroft and Gamble (2002).

\section{Results}

Testes of young rabbits (one month age):

Sections of the testes of young animals (one month age) revealed loose areolar tunica albuginea rich with fine blood vessels, and have small seminiferous tubules with regular outlines of Sertoli cells and spermatogonia. No any stages of spermatogenesis were present. The lumens were demonstrated empty from spermatozoa. The interstitia were made up of loose connective tissue with Leydig cells (Fig. $1 \mathrm{a}-\mathrm{c})$.

\section{2-Testes of adult rabbits ( 6 months age):}

Sections of the testes of adult rabbits (6 month age) showed seminiferous lobules. Each one is made up by the germinal epithelial cells. Spermatogenesis is essentially an elaborate cell differentiation process starting with the cuboidal germ cells known as spermatogonia layers, it is the outer most layer of germinal epithelium located on the basement membrane and mature into large polyhedral cells called primary spermatocytes, secondary spermatocytes which mature into small polyhedral cells known as spermatids that mature into spermatozoa as they move into the central lumen of the seminiferous tubules (Fig. 2a\&b). .

Supporting Sertoli cells are interspersed between the germinal epithelial cells within the seminiferous tubules. Between the seminiferous tubules, there are a large of polyhedral cells located in the connective tissue, known as interstitial Leydig cells. They are irregulary in shape and commonly have more than one nucleus and surrounded by a numerous blood vessels (Fig. 2b).

\section{3 - Testes of aged rabbits ( 2 years age):}

Sections of aged rabbit testes demonstrated thickness of tunica albuginea with congested blood vessels.The increment of thickness of the basement membrane connective tissue surrounding the seminiferous tubules was seen. The interstitia between the tubules were widened and filled with degenerated reduced Leydig cells. The atrophied seminiferous tubules appeared irregularly in shape and contained intertubular large space. Vacuoles were visible in disarranged spermatogenic cells. A reduction of spermatogenic cells was also seen. Sloughing of spermatogenic cells into the tubular lumen with decrease and degenerated spermatozoa was seen. The lumens of many tubules contained few spermatozoa and others illustrated completely empty from spermatozoa (Fig. 3a-d).

\section{4-Testes of aged rabbits treated with vitamin $E$ :}

The testes of aged rabbits administered with vitamin $\mathrm{E}$ at a dose $10 \mathrm{mg} / \mathrm{kg}$ b.w /d for 60 days demonstrated an obvious improvement of spermatogenic cells. Seminiferous tubules had well organized primary, secondary spermatocytes and spermatids. Spermatozoa appeared in the lumen of many seminiferous tubules (Fig. 4a\&b). 

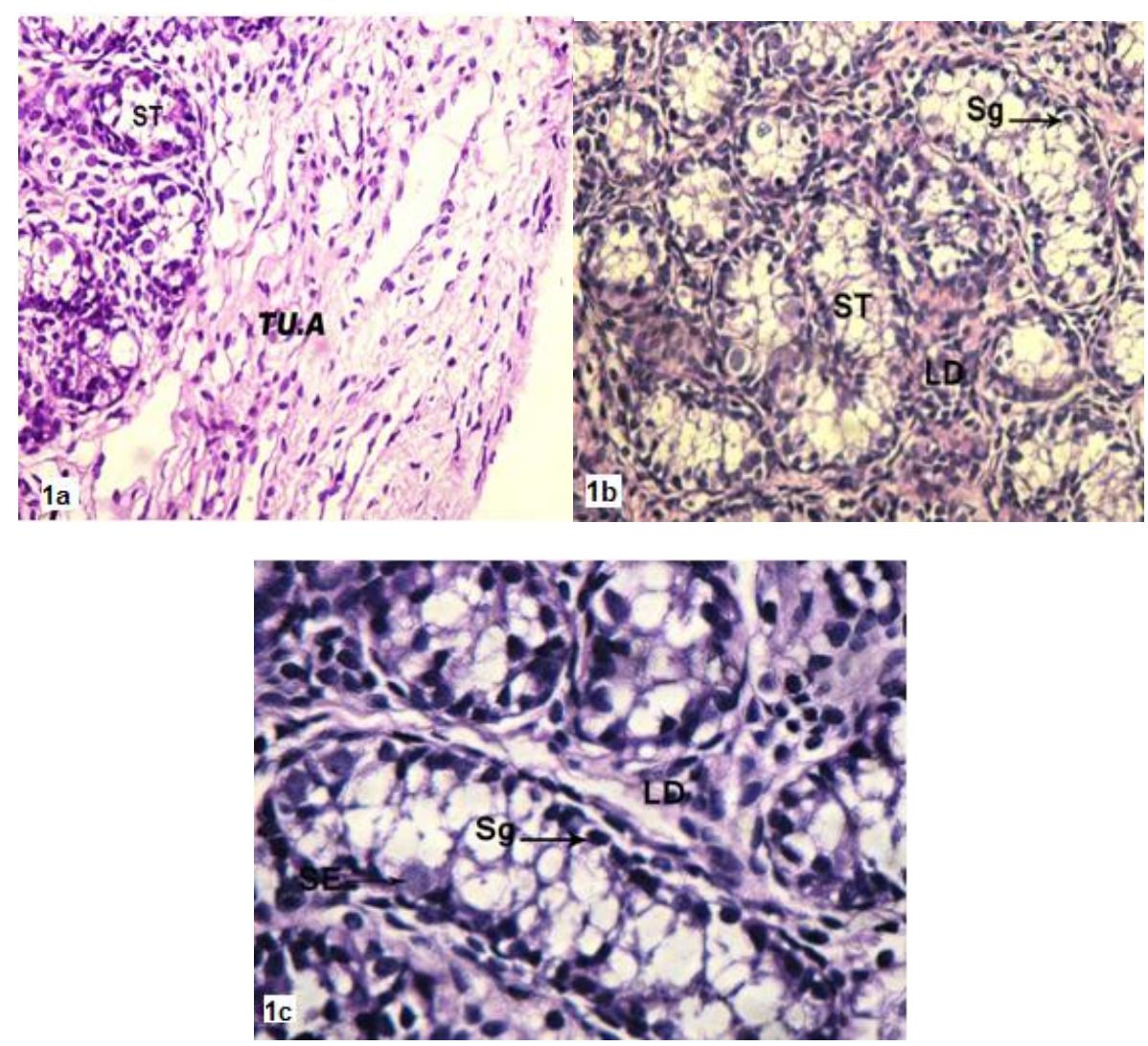

Fig. (1a-c): Sections in the testes of young rabbits ( one month age) stained with H\&E showing: a) tunica albuginea (TU.A) with loose connective tissue and small seminiferous tubules (ST). X200; b) small seminiferous tubules (ST) contain spermatogonia (Sg) only and interstitial tissue with Leydig cells (LD). X 200; c) Sertoli cell (SE), X400

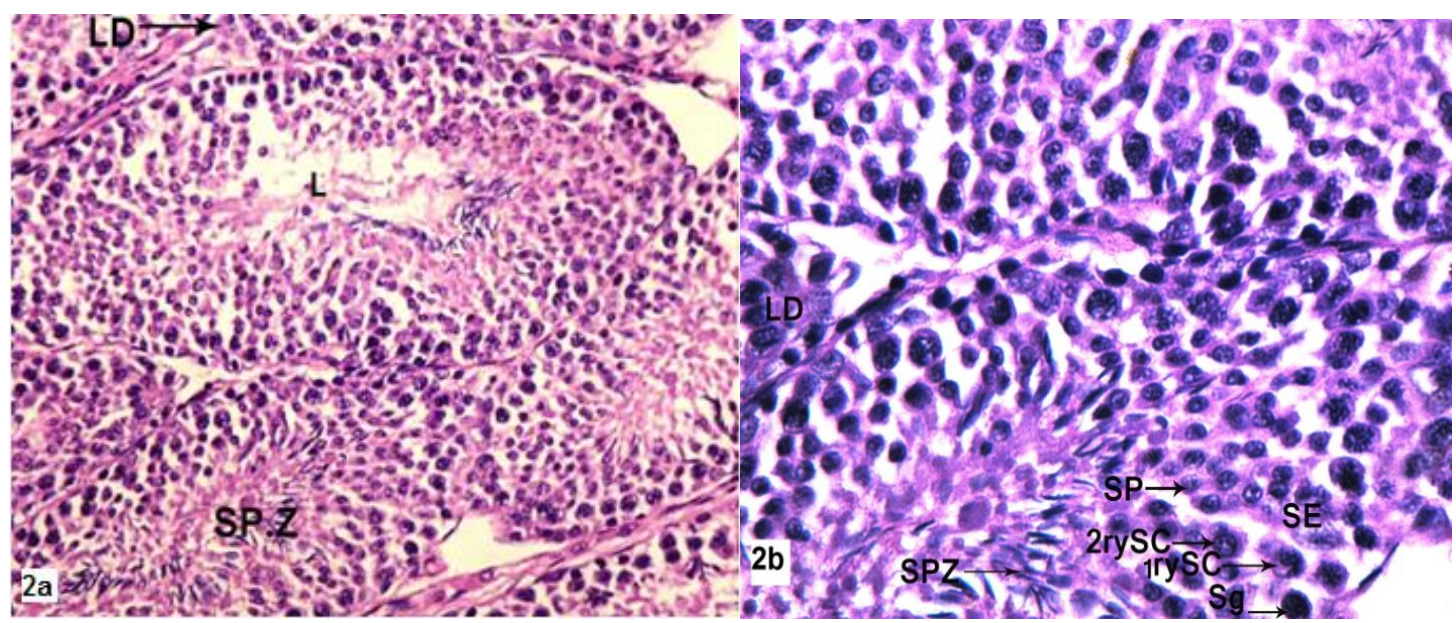

Fig. (2a\&b): Sections in the testes of adult rabbits stained with H\&E showing seminiferous tubules having various types of spermatogenic cells; spermatogonia (Sg), primary spermatocytes (1rySc), secondary spermatocytes (2rySc), spermatids (SP) and spermatozoa (SPZ) in the lumen (L). Leydig (LD) and Sertoli (SE) cells are also seen. X200 \& X400. 


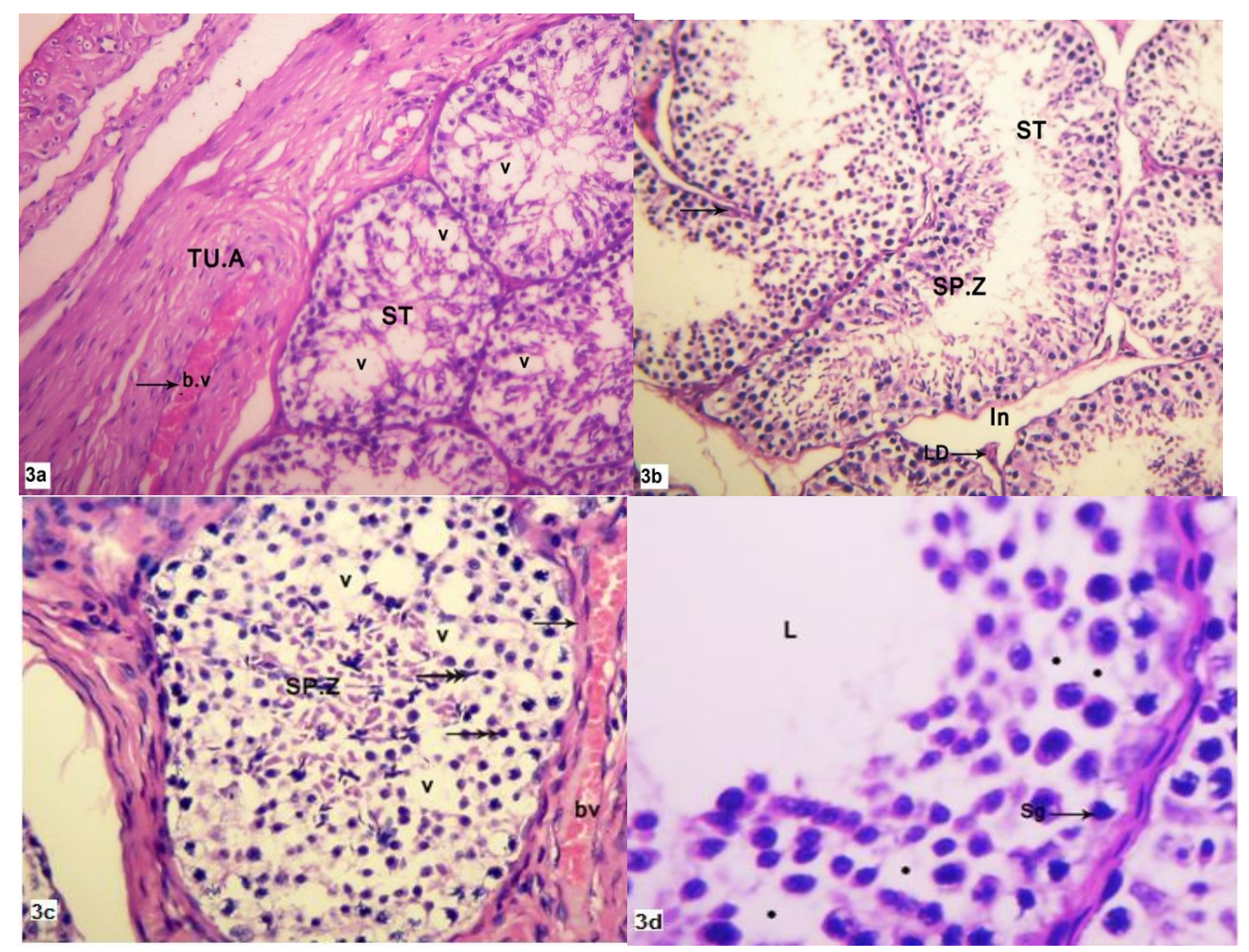

Fig. (3a-d): Sections in the testes of aged rabbits stained with H\&E showing: a) thick tunica albuginea (TU.A) with congested blood vessel (bv) and vacuolated spermatogenic cells (v) in the seminiferous tubules (ST). X100; b) fusion of the some seminiferous tubules (ST) (arrow), reduction of the spermatozoa (SP.Z) and degeneration of Leydig cells (LD) in widen interstitial tissue (In). X100; c) disarrangment of spermatogenic cells, vacuoles (V), pyknetic nuclei (double arrows) ,sloughing of germ cells into the tubular lumen and few spermatozoa (SP.Z). Boundary thickness of seminiferous tubules (arrow) and congested blood vessel (bv) are seen. X200; d) spacing between germinal cells (*) and spermatogonia (Sg). A clear absence of spermatozoa and widen of the lumen (L) are observed. X400

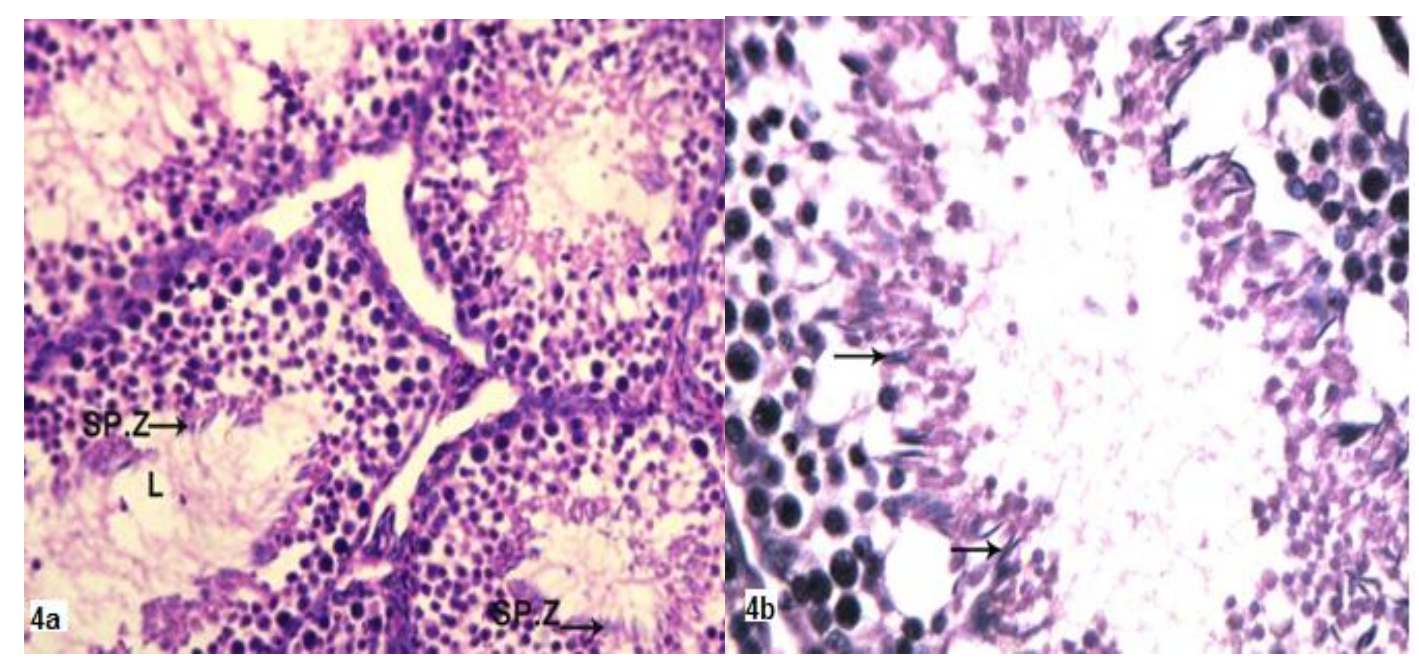

Fig. (4a\&b): Sections in the testes of aged rabbits administered with vitamin E stained with H\&E showing: a) improvements in the spermatogenic cells. The appearance of spermatozoa (SP.Z) in many seminiferous tubules is noticed in the lumen (L); b) a seminiferous tubule with a partial recovery of normal appearance of most various stages of spermatogenic cells and spermatozoa (arrows).Vacuolation and degeneration of spermatogenic cells are still present. X200 \& X400, respectively. 


\section{Discussion}

The peresent work studied the histological testes structure of different ages; young, adult \& aged New Zeland rabbits. The young individuals (one month age) illustrated a small form of seminiferous tubules with regular outline and having only spermatogonia at the basement membrane, no appearance of any stages of spermatogenesis, and the lumen appeared empty from spermatozoa. A number of Leydig cells were present in the interstitial tissue inbetween seminiferous tubules. This finding appeared to be applicable to the finding of Ahmad et al. (2010); Reddy et al. (2012) and Al-Kawmani et al. (2014).

The adult studied animals (6 months age) in the present investigation showed a normal spermatogenesis arrangement in 5 to 6 layers of germ cells with different cell types; spermatogonia, primary spermatocytes, secondary spermatocytes ,spermatids and spermatozoa which were seen in the lumens of the tubules. The interstitial Leydig cells were present inbetween the seminiferous tubules, Sertoli cells were seen laying on the basement membrane. These findings were in agreement with many authors; Wolf et al. (2000) in black-footed ferret (Mustela nigripes); Bin-Dohaish et al. (2008) in mice; Oner and Mehmet (2008) in Ram lambs; Halawa (2010) in albino rats; Al-Kawmani et al.( 2014) in Najdi Ram Lambs, and Talaat (2016) in New Zeland rabbits. The spermatogenesis is an organized process through the life of the male testes (Cheng et al., 2010), it does not occur simultaneously in all seminiferous tubules but rather in wave-like sequences of maturation, referred to as cycles of the seminiferous epithelium.

The present study demonstrated in aged rabbit testes (2 years age), many atrophied tubules with arrested spermatogenesis, disarrangment of spermatogenic cells and decrease of germ cells in the epithelium. Sloughing of germ cells into the tubular lumen, reduction and degeneration of spermatozoa were also noticed. In accordance, age- related changes in spermatogenesis of the testis have been detected in mice (Gosden et al., 1982); in rats (Purvis et al., 1980; Johnson and Neaves, 1983), and in men (Rolf et al. (2010).

The aging-related atrophied changes in the seminiferous epithelium were interinsic to the testis, and did not due to a decline in exterinsic factors that regulate testis function, such as serum levels of gonadotropic hormones. In rodents, the atrophy of the seminiferous epithelium is primarily due to loss of spermatogenic cells, as aged rats develop a reduction of Sertoli cells (Humphreys, 1977) and in cats (Elcock, and Schoning, 1984). The decline in reproductive capacity and various other physiological changes were recorded in aged animals (Goldsmith, 2004\&2014). However, in aged humans, atrophy results in the seminiferous tubules were from a decrease both in numbers of Sertoli cells and in numbers of compacted spermatids per Sertoli cell (Johnson et al., 1984; Peteresen and Pakkenberg, 2000).
Johnson et al. (1984) in their quantitative studies revealed that daily sperm production was significanty lower in older (50-80 years) than in younger (20-48 years) men with similar testicular weight or lower testicular weight. Moreover, Samanta et al. (1999) demonstrated that the specific loss of germ cells in both humans and rodents could be due to aging-related changes intrinsic to germ cells. The loss of germ cells could result in part or completely from a decreased ability of Sertoli cells to support germ cell survival and differentiation. Such agingrelated changes in Sertoli cell function might be reflected in specific alterations in the steady state levels of particular Sertoli cell transcripts, morphologically normal, partially regressed (contained fewer spermatogenic cells than a normal tubule) and fully regressed (contained no spermatogenic cells).

The loss of Leydig cells in aging testes resulted from dedifferentiation rather than from cell death and dissolution, then the population of other interstitial cells might be expected to increase with age (Zirkin and Strandberg, 1984; Levy and Robaire, 1999). This possibility has been examined in a series of men between 20 and 76 year of age who were known to have experienced a significant age-related decline in their Leydig cell population (Obregón and Ramírez, 1997). Leydig cells disappeard from the adult human testis as a function of increasing age, but the fate of the lost cells is unknown. Leydig cells are through to appear in the pubertal testis by differentiation from mesnechymal cells resembling fibroblasts. Similar undifferentiated cells are found in the adult human testis, raising the possibility that Leydig cells disappeard by dedifferentiation back into interstitial cells resembling fibroblast (Samanta et al., 1999).

In the present results, the elder animals treated with vitamin $\mathrm{E}$ at a dose of $10 \mathrm{mg} / \mathrm{kg}$ b.w / day for 60 days revealed that the testes were improved and the spermatogenesis process was organized, increased spermatozoa, and the thickness of basement membrane was decreased. The supplementing vitamin E increased total sperm output and sperm concentration in boars (Brezezińska-Slebodzińska et al., 1995), in rabbits (Yousef et al., 2003) and in rams and aohan fine-wool sheep (Hailing et al., 2004).

Vitamin $\mathrm{E}$ is considered the most effective lipid soluble antioxidants that react with polyunsaturated fatty acids in the cell membrane inhibiting the reactive oxygen radical production (Stagle and Gross, 1988). It might be thought that vitamin $\mathrm{E}$ protected the testes against the reactive oxygen radical generation which were over producted in aging and protected the spermatozoa from such damage (Chen et al., 2005). The oxidative damage has been implicated to be a major factor in the decline in physiologic function that occured during the aging process (Van Remmen and Richardson, 2001). Because mitochondria are a primary site of generation of reactive 
oxygen species, they have become a major focus of research in this area. Increased oxidative damage to mitochondrial proteins, lipid and DNA has been reported to occur with age in several tissues in a variety of organisms (Goldsmith, 2014).

The free radical and mitochondrial theories of aging speculated that cumulative damage to mitochondria and mitochondrial DNA (mtDNA) caused by reactive oxygen species that is one of the causes of aging. Oxidative damage affects replication and transcription of mtDNA and results in a decline in mitochondrial function which in turn leads to enhance free radicals (Cui el al., 2012).

Moreover, Yan et al. (2010) found that supplementing the diet with vitamin E improved testicular marker enzymes activity: significantly increased the activity of testicular mitochondrial ATPase, lactate dehydrogenase, sorbitol dehydrogenase and alkaline phosphatase. Hong et al. (2010) found that the supplementation of vitamin E can increase activity of glutathione peroxidase (GSH-PX) and can protect testis from damage by preoxidation. Vitamin E could up- also regulate genes expression responsible for sperm mobility in the testis of the aging mouse (Mohammadi et al., 2013). In the previous study, aged rabbits (2 years age) exhibited a numerous number of irregular follicles lined with flattened thyrocytes, and after supplementation with vitamin E at a dose $10 \mathrm{mg} / \mathrm{kg}$ b.w / day for 60 days, an obvious improvement of the thyroid structure and the restoration of their simple cuboidal thyrocytes shape and the cytoskeletal vimentin and cytokeratin immunoreactivity were expressed (El-Desouki et al., 2014).

In conclusion, the administration of vitamin $\mathrm{E}$ at a therapeutic dose to the aged rabbits strikingly restored the histological structures of the testes, an obvious improvement of Leydig and spermatogenic cells; seminiferous tubules became well organized with primary, secondary spermatocytes and spermatids and many spermatozoa appeared in the lumens of seminiferous tubules. Therefore, the present study recommends that the senescent New Zeland rabbits should be given vitamin $\mathrm{E}$ to improve the disorders of male fertility and to increase offspring of these animals.

\section{References}

Agostinucci, K.; Manfredi, T. G.; Cosmas, A.; Martin, K.; Han, S. N. ; D. Wu, D.; Sastre, J.; Meydani, S. N. and Meydani. M. (2002): Vitamin E and age alter liver mitochondrial morphometry. J. Anti. Aging Med., 5 (2): 173-178.

Ahmad, N.; Umar, S.; Shahab, M. and Arslan, M. (2010): Testicular development and establishment of spermatogenesis in Nili -Ravi buffalo bulls (Bubalus bubalis). Theriogenology, 73 (1): 20-25.

Al-Kawmani, A. A.; Alfuraiji, M. M.; AboTarboush, F. M.; Alodan, M. A. and Abul Farah, M. (2014): Developmental changes in testicular interstitium in the Najdi Ram Lambs. Saudi J. Biol. Sci., 21(2): 133-137.
Arking, R. (2006): Biology of Aging, Observation and Principle, $3^{\text {rd }}$ Edn, Published by Oxford Univ. Press, Inc.

Bancroft, J. D. and Gamble, M. (2002): Theory and Practice of Histological Techniques, 5th edn, ChurchillLivingstone. London.

Baydas, G.; Canatan, H. and Turkoglu, A. (2002): Comparative analysis of the protective effects of melatonin and vitamin $\mathrm{E}$ on streptozotocin- induced diabetes mellitus. J. Pineal Res., 32(4): 225-230.

Bin Dohaish, E.; Ali, A. and Melebary, S. (2008): Histological changes in the testes of two strains of mice:Effect of ecological factor.Saudi J. Biol. Sci.,15 (2) :279-287.

Brezezińska-Slebodzińska, E.; Slebodzinski, A. B.; Pietras, B. and Wieczorek, G. (1995): Antioxidant effect of vitamin $\mathrm{E}$ and glutathione on lipid peroxidation in boar semen plasma. Biol. Trace. Elem. Res., 47(1-3):69-74.

Chen, H.; Liu, J.; Luo, L.; Baig, M. U.; Kim, J. M. and Zirkin, B. R. (2005): Vitamin E aging and Leydig cell steroidogenesis. Exp. Gerontol., 40 (8-9): 728-736.

Cheng, C. Y.; Wong, E. W.; Yan, H. H. and Mruk, D. D. (2010): Regulation of spermatogenesis in the microenvironment of the seminiferous epithelium: new insights and advances. Mol. Cell Endocrinol., 315 (1-2): 49-56.

Cui, H.; Kong, Y. and Zhang, H. (2012): Oxidative stress, mitochondrial dysfunction, and aging. J. Signal Trans., volume 2012: 1-13.

Dakouane, M.; Bicchieray, L.; Bergere, M.; Albert, M.; Vialard, F. and Selva, J. (2005): A histomorphometric and cytogenetic study of testis from men 29-102 years old. Fertil. Steril., 83 (4) : 923-928.

Elcock, L. H. and Schoning, P. (1984): Agerelated changes in the cat testis and epididymis. Am. J. Vet. Res., 45 (11): 2380-2384.

El-Desouki, N. I.; Afifi, D. F.; El-Refaiy, A. I. and Talaat, H. (2014) : Age related change in hitological and cytoskeletal intermediate filaments in rabbits thyroid glands and the prophylactic role of vitamin E. Global Veter., 13 (4): 511-519

Goldsmith, C. T. (2004): Aging theories and their implication for medicine. J .Med. hypothes., 62 (2): 304308.

Goldsmith, C. T. (2014): An Introduction to Biological Aging. Theory Azinet Press, Second Edition, Theodore C. Goldsmith. $2^{\text {nd }}$ edn, Azinet Press.

Gosden, R. G.; Richardson, D. W.; Brown, N. and Davidson, D. W. (1982): Structure and gametogenic potential of seminiferous tubules in aging mice. J. Rep. Fer., 64:127-133.

Hailing, L.; Zhihai, J.; Shien, Z. and Jinzhi, D. (2004): Effect of vitamin $E$ on the qualities of fresh and frozen thawed ram semen. China Herbivores, 5: 14-16.

Halawa, A. M. (2010): Effect of silldenafil administration on ischemia/reperfusion of the testis in adult 
albino rat light and electron microscopic study. Egypt J. Histol., 33 (2): 380-395.

Hong, Z.; Hailing, L.; Hui, M.; Guijie, Z.; Leyan, Y. and Dubing, Y. (2010): Effect of vitamin E supplement in diet on antioxidant ability of testis in Boer Goat. Anim. Rep. Sci., 117 (1-2):90-94.

Humphreys, P. N. (1977): The histology of the testis in aging and senile rats. Exp.Gerontol., 12 (1-2): 27- 34.

Johnson, L. and Neaves, W.B. (1983): Enhanced daily sperm production in the remaining testis of aged rats following hemicastration.J. Androl., 4(2): 162-166.

Johnson, L.; Petty, C. S. and Neaves, W. B. (1984): Influence of age on sperm production and testicular weight in men. J. Rep. Fertil., 70: 211-218.

Levy, S. and Robaire, B. (1999): Segment-specific changes with age in the expression of junctional proteins and the permeability of the blood epididymis barrier in rats. Biol. Rep., 60 (6): 1392-1401.

Mahmood, I. M. (2008): Histological changes in testicular tissue with age.Tikrit. J. Pure Sci., 13(3).

Mohammadi, S.; Jalali, M.; Nikravesh, M. R.; Fazel, A.; Ebrahimzadeh, A.; Gholamin, M. and Sankian, M. (2013):.Effects of vitamin E treatment on CatSper genes expression and sperm quality in the testis of the aging mouse. Iran J. Rep. Med., 11 (12): 989-998.

Obregón, E.B. and Ramirez, O. (1997): Aging and testicular function in Octodon degus. Andrologia, 29 (6): 319-326.

Oner, O. and Mehmet, K. (2008): Histological investigation of testicular and accessory sex glands in Ram Lambs immunized against recombinant GnHR fusion proteins. Eur. J. Gen. Med., 5 (1):21-26.

Paniagua, R.; Nistal, M.; Amat, P.; Rodriguez, M. C. and Martin, A. (1987): Seminiferous tubule involution in elderly men. Biol. Rep., 36 (4): 939-947.

Ravindranath, N.; Dettin, L. and Dym, M. (2003): Mammalian.Testis:Structure and Function. In: Introduction to Mammalian Reproduction.Tulsiani (edn), Chapter (1):1-19.

Reddy, N.; Mahla, S. R.; Thathi, R.; Suman, K. S.; Jose, J. and Goel, S. (2012): Gonadal status of male recipient mice influences germ cell development in immature buffalo testis tissue Xenograft .Reproduction,143 :59-69.

Regadera, J.; Cobo, P.; García, F.; Nistal, M. and Paniagua, R. (1993): Testosterone immunoexpression in human Leydig cells of the tunica albuginea testis and spermatic cord.A quantitative study in normal foetuses, young, adult, elderly men and patients with cryptorchidism. Andrologia, 25 (3): 115-122.
Petersen, P. M. and Pakkenberg, B. (2000): Stereological quantitation of Leydig and Sertoli cells in the testis from young and old men. Image Anal. Stereol ., 19 (3) :215-218.

Purvis, K.; Clausen, O. P. and Hansson,V. (1980): Effect of age and hypophysctomy on responsiveness of rat Leydig cells to hCG. J. Rep.Fert., 60:77-86.

Rolf, C.; Zitzmann, M. and Nieschlag, E. (2010): The aging male and late-onset hypogonadism. In: Nieschlag E, Behre HM, Nieschlag S, (eds.), Andrology. Male Reproductive Health.and Dysfunction, $3^{\text {rd }}$ Edition, Springer-Verlag, Berlin,.Heidelberg, 239-261

Samanta, L.; Roy, A. and Chainy, G. B. (1999): Changes in rat testicular anti-oxidant defence profils as a function of age and its impairment by hexachlorocyclohexane during critical stages of maturation. Andrologia, 31 (2):83-90.

Shokri, S.; Hemadi, M. and Aitken, R. (2012): Transmission Electron Microscopy for the Quantitative Analysis of Testis Ultrastructure "Materials Science". The Transmission Electron Microscope Book edited by Khan Macrz. Chapter7.

Sönmez, M. Türk, G. and Yüce, A. (2005): The effect of ascorbic acid supplementation on sperm quality, lipid peroxidation and testosterone levels of male Wistern rats. Theriogenology, 63:2063-2072.

Stagle, T. A. and Gross, S. I. (1988): Vitamin E in nutrition during infancy. Henley and Belfus. Inc. Philadelphia, 277-288.

Talaat, H. F. (2016): Age- related changes in Mammalian endocrine glands and the prophylactic role of vitamin E. Ph.D, Faculty of Science, Tanta University

Van Remmen, H. and Richardson, A. (2001): Oxidative damage to mitochondria and aging. Exp.Gerontol., 36 (7) : 957-968.

Wolf, K. N.; Wildt, D. E.; Vargas, A.; Marinari, P. E.; Kreeger, J. S.; Ottinger, M. A. and Howard, J. G. (2000): Age- dependent changes in sperm production, semen quality, and testicular volume in the black- footed ferret Mustela nigripes. Biol. Rep., 63:179-187.

Yan, L.; Yue, D.; Luo, H.; Jin, X. and Xu, X. (2010): Effect of Vitamin E supplementation on the enzymatic activity of selected markers in Aohan fine-wool sheep testis. Anim. Rep. Sci., 122 (3-4):264-269.

Yousef, M. I.; Abdallah, G. A. and Kamel, K. I. (2003): Effect of ascorbic acid and Vitamin E supplementation on semen quality and biochemical parameters of male rabbits. Anim. Rep. Sci., 76 (1-2): 99111.

Zirkin, B. R. and Strandberg, J. D. (1984): Quantitative changes in the morphology of the aging canine prostate. Anat. Rec., 208 (2):207- 214. 